\title{
o debate sobre a reforma agrária no interior do pcb: as vertentes de alberto passos guimarães e caio prado jr. ${ }^{\star}$ the discussion on agrarian reform inside the pcb: the strands of alberto passos guimarães and caio prado jr.
}

\author{
Pedro Vilela Caminha $\star \star$ \\ Instituto de Economia, Universidade Federal do Rio de Janeiro, Rio de Janeiro, Rio de Janeiro, \\ Brasil
}

Resumo

$\mathrm{O}$ artigo apresenta o debate sobre a reforma agrária travado no interior do Partido Comunista Brasileiro (PCB) nas décadas de 1950 e 1960. Mostra que a vertente usual de reforma agrária - de Alberto Passos Guimarães - enfatiza a luta pela terra. E que uma vertente alternativa de reforma agrária - a de Caio Prado Jr. - enfatiza a luta por trabalho. Ao fim, o artigo conclui destacando a possível importância do debate teórico entre essas vertentes de reforma agrária para a orientação prática seguida pelo PCB ao longo das décadas de 1950 e 1960.

Palavras-chave: Reforma agrária. Partido Comunista Brasileiro. Caio Prado Jr.

\section{Abstract}

This article presents the discussion on agrarian reform inside the Brazilian Communist Party (PCB) in the 1950s and 1960s. It shows that the usual aspect of agrarian reform - by Alberto Passos Guimarães - emphasizes the struggle for land. And that an alternative aspect of agrarian reform - that of Caio Prado Jr. - emphasizes the struggle for work. Finally, the paper concludes by highlighting the possible importance of the theoretical debate between these agrarian reform strands and the practical orientation followed by the PCB throughout the 1950s and 1960s.

Keywords: Agrarian reform. Brazilian Communist Party. Caio Prado Jr.

* Artigo derivado de parte do capítulo 2 da Tese de Doutorado submetida ao Programa de Pós-Graduação em Economia da Indústria e da Tecnologia da Universidade Federal do Rio de Janeiro (PPGE/UFRJ). O autor agradece o auxílio do Conselho Nacional de Desenvolvimento Científico e Tecnológico (CNPq). As opiniões, hipóteses e conclusões ou recomendações expressas neste material são de responsabilidade do autor e não necessariamente refletem a visão da sua instituição. Submetido: 29 de junho de 2017; aceito: 3 de outubro de 2018.

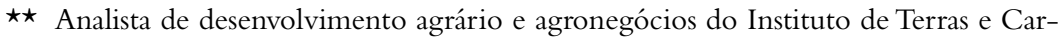
tografia do Estado do Rio de Janeiro (ITERJ). Doutor em Economia pela UFRJ. E-mail: pedrovcaminha@gmail.com 


\section{Introdução: o debate sobre a reforma agrária no PCB}

Este artigo tem o objetivo de apresentar as vertentes de reforma agrária representadas por dois dos principais intelectuais do PCB nas décadas de 1950 e 1960: Alberto Passos Guimarães e Caio Prado Jr. Essas vertentes de reforma agrária eram debatidas no interior do PCB desde as décadas de 1940 e 1950, embora alcançassem seu "clímax" na vida política nacional apenas na década de 1960, parafraseando Florestan Fernandes (1974, p. 3).

Por essa origem de longa data, não se faz necessário fazer referência à cisão, no final da década de 1950, que criaria o atual PCdoB. É suficiente falar que o PCB de que trata este artigo é o que ficou conhecido na historiografia social e política brasileira como o "Partidão", de Luís Carlos Prestes, Astrojildo Pereira e, é claro, os dois intelectuais apresentados aqui (Vinhas, 1982).

De acordo com Santos, "alguns intelectuais brasileiros adquirem outro realce quando lidos a partir do campo de destino de muitos de seus escritos - o [...] Partido Comunista Brasileiro (PCB). É o caso de Alberto Passos Guimarães e Caio Prado Jr." (Santos, 2007b, p. 13). A associação entre o pensamento econômico desses intelectuais e os seus escritos de intervenção política na estratégia do partido "permite-nos dizer, certamente de modo paradoxal, que esses autores são os mais expressivos testemunhos dos êxitos do PCB” (Santos, 2007b, p. 13).

Em linhas breves, Alberto Passos Guimarães teve sua importância inscrita no debate sobre a reforma agrária no Brasil, na medida em que ele era o intelectual que procurava fornecer uma fundamentação teórica para a estratégia de luta no campo seguida pelo PCB nas décadas de 1950 e 1960. Guimarães era, pode-se chamar assim, um "intelectual orgânico" do partido, utilizando a expressão de Gramsci ${ }^{1}$.

1 Alberto Passos Guimarães nasceu em Maceió, em 16 de abril de 1908, e faleceu no Rio de Janeiro, em 24 de dezembro de 1993. Sem formação acadêmica, largou a escola aos 9 anos de idade para ajudar o seu pai, antes mesmo de concluir o curso secundário. A partir daí foi autodidata para o resto da vida. Em Maceió, trabalhou como comerciante e jornalista, onde fez parte da cena intelectual da época, ao lado de Graciliano Ramos, Aurélio Buarque de Holanda, Rachel de Queiroz eValdemar Cavalcanti. Em 1931 fundou, juntamente com este último, a revista Novidade. De acordo com Barros, "esse periódico abriu novos caminhos para os jovens intelectuais de Alagoas e até hoje essa revista é uma referência no meio acadêmico e literário" 
Barros (2008, p. 3). Segundo o historiador Geraldo de Majella, com essa e outras iniciativas, Alberto Passos Guimarães "foi um intelectual que deixou grandes marcas na cultura de Alagoas, ao fundar a revista Novidade e ao participar como jornalista de vários jornais operários. Por esses feitos, já é merecedor da nossa admiração e mais ainda pela sua participação na União Brasileira de Escritores e como diretor de publicações como Para Todos, O Momento, entre outras" (Majella, apud Barros, 2008, p. 3-4). Ainda em 1931, Guimarães filiou-se ao Partido Comunista do Brasil (PCB, de Luís Carlos Prestes, Oscar Niemeyer e Jorge Amado, dentre outros). "A atuação como jornalista no jornal $A$ Vanguarda Operária é uma evidência da sua ligação com o movimento operário alagoano. Por esse motivo, foi perseguido e viveu na clandestinidade, tendo que sair de Maceió" (Barros, 2008, p. 2). Em 1940, fugindo de perseguição política, mudou-se para Salvador, e em 1945 fixou-se no Rio de Janeiro. Na capital federal, trabalhou inicialmente como representante comercial de sua pequena firma, a Organização Brasil Ltda. Já na década de 1950, ia trabalhar no Instituto Brasileiro de Geografia e Estatística (IBGE) e, no final da década de 1960, na Rede Ferroviária Federal. Assim, Guimarães "foi um ibgeano que ultrapassou os limites do Instituto, brilhando diante do país e fora dele" (Santos, 2014, p. 564). Ao ser forçado a se aposentar pelo regime instaurado em 1964, foi convidado por Antônio Houaiss para participar do projeto e da redação da Enciclopédia Mirador, do grupo Enciclopédia Britânica do Brasil. No ano do seu centenário, Guimarães emprestou seu nome à biblioteca do Instituto de Terras e Reforma Agrária de Alagoas (ITERAL). Para o presidente do ITERAL, Geraldo de Majella, "a homenagem que prestamos a Alberto Passos Guimarães na passagem do seu centenário de nascimento, dando o nome da biblioteca do ITERAL, é o mínimo que podemos fazer em reverência a sua memória e a sua enorme contribuição como intelectual da questão agrária no Brasil" (Majella, 2008, apud Barros, 2008, p. 3).A Biblioteca Alberto Passos Guimarães foi inaugurada com a presença do filho do intelectual comunista, o físico Alberto Passos Guimarães Filho, que atualmente trabalha no Centro Brasileiro de Pesquisas Físicas (CBPF). Para o cientista, o esforço de seu pai para compreender as questões da agricultura e da reforma agrária no Brasil estava associado à sua paixão pela justiça social, o que o levou a ser um militante político por toda a vida. "Parte desse esforço era para conhecer os dados brutos sobre o Brasil, de um lado, e de outro armar ferramentas de análise para compreender essa realidade. Um esforço desse tipo, que culminou com o lançamento do livro Quatro séculos de latifúndio, nos coloca hoje diante de uma realidade totalmente diferente, em que a reforma agrária está em curso no Brasil. Os grandes problemas associados a ela existem, mas a sociedade compreende hoje o que apenas uma minoria vislumbrava naquela época: que a terra é um patrimônio que deve servir a toda a sociedade", analisou Alberto Passos Guimarães Filho (Barros, 2008, p. 4). Alberto Passos Guimarães deixou obras de relevância para o estudo da economia e política agrária brasileira, tais como Inflação e monopólio no Brasil: por que sobem os preços?, de 1962; de 1963 é sua principal obra, Quatro séculos de latifúndio. Em 1979, publicaria A crise agrária, e, em 1982, As classes perigosas: banditismo rural e urbano. Durante toda a sua vida, Guimarães foi militante do PCB. Em particular, teve atuação de destaque como intelectual e profissional da imprensa do partido. Como profissional da imprensa do PCB, trabalhou no jornal Imprensa Popular, no semanário sobre cultura Para Todos - dirigido por Jorge 
Nos debates sobre a reforma agrária travados no interior do PCB, Caio Prado Jr., por sua vez, era o maior crítico da estratégia comunista. Prado Jr., tendo como base uma interpretação singular sobre a formação econômica do Brasil contemporâneo, enfatizava a necessidade do seu Partido Comunista priorizar vertentes alternativas de luta no campo (Santos, 2001, cap. 7) $)^{2}$. Dessa forma,

Amado e Oscar Niemeyer - e foi diretor do jornal Hoje. Ainda como "intelectual orgânico" do partido, Guimarães teve participação central na redação do documento conhecido como "Declaração de março" de 1958. Esta produziu uma inflexão na prática política do $\mathrm{PCB}$, que passou a atribuir maior relevância à participação no jogo democrático. "Na década de 1950 e no começo dos anos de 1960, uma série de situações, como a crise do stalinismo e o fomento do nacionalismo no Brasil, acentuaram divergências em torno da análise que o partido realizava sobre o país e as medidas que defendia para sua transformação social. Alberto Passos Guimarães, bem como Caio Prado, participaram desse período de discussões, se posicionando no debate político e, desse modo, expondo as cisões que ocorriam no PCB" (Barros, 2008, p. 2). Em resumo, pode-se dizer, como faz Paulo Décio, que a biografia de Alberto Passos Guimarães caracteriza o intelectual alagoano como "um ensaísta agrário e um militante comunista. Ele tentava mobilizar os setores camponeses num processo de desenvolvimento social pela via democrática” (apud Barros, 2008, p. 4).

2 Caio Prado Jr. nasceu na cidade de São Paulo, em 1907, onde veio a falecer em 1990. De acordo com Ricupero (2012), a família Prado fazia parte da aristocracia paulista, o que permitiu a Prado Jr. estudar nos melhores colégios jesuítas, cursar direito na Universidade de São Paulo (USP) e passar uma estadia na Inglaterra, ainda com 21 anos. Para Ricupero (2012), Caio Prado Jr. era, assim, "um menino da elite paulista”, que logo se viu atraído pela política. Formou-se em 1928, quando se filia ao Partido Democrático de São Paulo, de oposição ao Partido Republicano Paulista. Logo a seguir, o partido ia fazer parte da Aliança Liberal, que votou em Getúlio Vargas em 1929. Nessa campanha, ocorreu a primeira prisão de Caio Prado Jr., em razão de uma "provocação juvenil": em comício de Júlio Prestes, berrou:"VivaVargas!”.Ainda segundo Ricupero (2012), no ano seguinte, Prado Jr. participaria da conspiração de 1930 e se tornaria procurador no interior de São Paulo. Mas logo se desilude com os rumos do movimento e em 1931 se filia ao PCB, partido em que manteria sua militância por toda a vida. Ainda na década de 1930, participaria da fundação da Associação Brasileira de Geógrafos, que viria a ser a primeira entidade científica de caráter nacional. Em novembro de 1935, quando a Aliança Nacional Libertadora (ANL) é posta na ilegalidade, Prado Jr. participa da Intentona Comunista, o que o leva à prisão pela segunda vez. Dessa vez, vai para o exílio na França e, em 1937 e 1938, presta apoio, na fronteira, aos republicanos da Revolução Espanhola. Em 1945, Prado Jr. é eleito deputado estadual pelo PCB em São Paulo. No entanto, teria seu mandato cassado em 1948, após o seu PCB ser posto na ilegalidade por receber financiamento ilegal - ouro de Moscou - do Partido Comunista da União Soviética (PCURSS). Ainda segundo Ricupero (2012), Prado Jr. prestou concurso para ser professor da Universidade do Estado de São Paulo (USP) por duas vezes. Em 1954, quando a Faculdade de Economia e Administração (FEA) era ultraconservadora, 
enquanto o historiador de São Paulo, Caio Prado Jr., percorre "como um alter ego" grande parte da trajetória do PCB, [...] Alberto Passos Guimarães emerge como um intelectual influente na área pecebista mais contemporânea, tendo papel importante particularmente na [sua] "nova política". (Moita; Strotopasolas, 2008, p. 220)

O debate entre esses dois intelectuais brasileiros de grande repercussão nas décadas de 1950 e 1960 já foi abordado em Caminha (2008). Por isso, o presente artigo apresenta de maneira apenas sumária o debate entre as vertentes de reforma agrária representadas pelos dois autores, expondo primeiro a estratégia de luta no campo proposta por Guimarães, e a seguir, a de Prado Jr.

a banca, sem ter o que fazer, nem aprovou nem reprovou: conferiu-lhe o título de livre-docente. E a segunda vez foi em 1968-1969, quando a cátedra de história da Faculdade de Filosofia ficou vaga, em razão da aposentadoria compulsória de Sérgio Buarque de Holanda. Dessa vez, na data prevista, a USP suspendeu o concurso. De acordo com Ricupero (2012), a primeira obra de importância de Caio Prado Jr. foi Evolução política do Brasil, de 1933 - isto é, no mesmo ano de Casa-grande E senzala, de Gilberto Freyre. Em Evolução política do Brasil, Prado Jr. faz um ensaio geral de interpretação da história do Brasil, criticando a historiografia então existente.Ainda assim, seria Formação do Brasil contemporâneo, de 1942, a sua principal obra (atualizada, em 1946, com História econômica do Brasil, e com uma última ampliação em 1970). Em sua obra máxima, o historiador de São Paulo rompe com a historiografia oficial, assim como com as doutrinas da III Internacional Comunista. Ao mesmo tempo, também explicitava suas diferenças com relação às interpretações de Casa-grande $\mathcal{E}$ senzala, de Gilberto Freyre, e de Raízes do Brasil, de Sérgio Buarque de Holanda, de 1937 - que, com a Formação do Brasil contemporâneo, de Prado Jr., são consideradas as obras fundadoras do "moderno pensamento social brasileiro". A partir de 1955, Prado Jr. ia editar a Revista Brasiliense, periódico que se tornaria "uma das publicações mais importantes da esquerda brasileira nos anos 50 e início dos 60" (Mantega, 1984, p. 236). Nas páginas da Brasiliense se debateriam "os problemas políticos do dia, notadamente os do país, abordando todos os assuntos. Reuniu muito do melhor da intelectualidade nativa, de modo que sua coleção é um bom retrato da época, do que pensou e viveu o Brasil" (Iglésias, 1982, p. 19). Regularmente, ao longo de suas 52 edições pela Revista Brasiliense, debater-se-iam temas de destaque no Brasil e no mundo, até março de 1964. Em abril de 1964, Prado Jr. seria preso pela terceira vez - dessa vez, por ser intelectual assumidamente marxista, filiado ao PCB. Segundo Oliveira (2007,p. 124-125), pelas páginas da Brasiliense iam ser publicadas as principais contribuições do historiador de São Paulo sobre a questão da política de "reforma agrária" no Brasil. Em resumo, portanto, é possível dizer que a biografia de Caio Prado Jr. caracteriza o autor tanto pela militância política quanto pela produção intelectual, geralmente voltada para a interpretação e intervenção sobre o que era então denominado como "a realidade brasileira", particularmente sua agricultura. 
Antes de prosseguir na exposição que se segue, cabe notar que ambos os autores têm como referência teórica principal a dialética entre forças produtivas e relações de produção, apresentada no Prefácio da Contribuição à crítica da economia política, de Marx (1859). No entanto, Guimarães (1963), com uma suposta reminiscência "feudal" na agricultura brasileira, se esforça por justificar uma "revolução democrático-burguesa" no Brasil. Dessa forma, a luta "camponesa" contra o monopólio "feudal" da propriedade da terra nos Quatros séculos de latifúndio, que Guimarães (1963) se esforça por justificar ainda na década de 1960, está em conformidade com a orientação política da III Internacional Comunista, de 1928.

Já Prado Jr. (1942) enfatiza a debilidade da luta pela terra da agricultura familiar "camponesa" no curso singular da Revolução Brasileira, e por isso se esforça por sugerir uma estratégia alternativa de reforma agrária na agricultura nacional: em torno da luta por melhorias nas condições de trabalho imperantes na agricultura patronal do "agronegócio”. Essa estratégia alternativa de reforma agrária, justificada pela debilidade da luta de classes "mal definidas" pela terra "camponesa", é exposta na Formação do Brasil contemporâneo, de Prado Jr. (1942), e foi objeto de análise detalhada e específica em Caminha (2007).

Finalmente, é importante lembrar que, nas décadas de 1950 e 1960, o debate sobre a reforma agrária dizia respeito a uma das principais bandeiras de luta da sociedade brasileira em geral, e do PCB em particular. Essas distintas vertentes de reforma agrária eram debatidas em tribunas, periódicos e congressos, e ensejavam também uma reflexão sobre a própria "realidade nacional” no vocabulário da época (Linhares; Teixeira, 1981, p. 38).

Por essa ênfase no pensamento da época, de cada autor e sua respectiva vertente de luta no campo, o artigo apresenta suas bases teóricas e paradigmas históricos. Também se apresenta os respectivos lócus de luta na formação econômica do Brasil, seus exemplos históricos de reforma agrária e os possíveis efeitos que cada estratégia podia produzir sobre o desenvolvimento econômico e tecnológico nacional.

As distintas experiências empíricas de medidas de política agrária preconizadas por cada vertente já foram abordadas em Caminha (2009). Por isso, o presente artigo apenas menciona a principal medida de política agrária priorizada em cada vertente, tendo em vista, como dito, o objetivo de concentrar-se no seu debate teórico ${ }^{3}$.

3 Em Medeiros (1995) já se pesquisou a evolução da visão da imprensa comunista sobre 
Por fim, a título de conclusão, o artigo aponta uma possível síntese desse debate sobre a reforma agrária expressa na orientação prática seguida pelo PCB ao longo das décadas de 1950 e 1960. E, como Apêndice, inclui-se um Quadro-síntese sobre os eixos teóricos orientadores de cada estratégia de reforma agrária abordada. Na medida do possível, também se procura retirar do vocabulário dos autores a linguagem típica da "Guerra Fria", procurando-se, sem anacronismos, manter o que pode ser aproveitado desse sui generis debate agrário nacional.

\section{A estratégia usual de reforma agrária: a luta pela terra}

Segundo Freitas Filho, "um dos mais expressivos representantes da corrente dualista no Brasil foi Alberto Passos Guimarães, com a obra Quatro séculos de latifúndio, publicada em 1963” (Freitas Filho, 1988, p. 19). Nessa obra, o autor procura fornecer uma fundamentação teórica sobre uma suposta reminiscência "feudal", ou não inteiramente "capitalista", na formação econômica da agricultura brasileira.

A questão agrária, com a reafirmação da tese da feudalidade, confere a Alberto Passos Guimarães inscrição entre os constituintes do modelo democrático-burguês de interpretação pecebista do Brasil contemporâneo.É com Quatro séculos de latifúndio que ele ficará conhecido na cena intelectual da esquerda daqueles anos 60, e terá, desde então, presença representativa na historiografia agrária brasileira. (Santos, 1994, p. 53)

É de extrema importância lembrar que "afirmar o caráter feudal da economia colonial naquele momento era também uma questão política, pois implicava na formulação de estratégias de ação transformadoras da estrutura agrária do país" (Freitas Filho, 1988, p. 21). Como o autor destacava logo no início de Quatro séculos de latifúndio,

a simples eliminação em nossa História da essência feudal do sistema latifundiário brasileiro e a consequente suposição de que iniciamos nossa vida

as diferentes vertentes de luta pela reforma agrária, e Costa (1991) já entrevistou militantes comunistas que participaram diretamente dessas lutas agrárias. Por isso, a metodologia da presente pesquisa deu preferência à análise comparativa do pensamento dos dois principais intelectuais comunistas do período e seus comentaristas. 
econômica sob o signo da formação social capitalista significa, nada mais nada menos, considerar uma excrescência, tachar de supérflua qualquer mudança ou reforma profunda de nossa estrutura agrária.

Supondo-se inicialmente capitalista o regime econômico implantando no Brasil-Colônia, estaria implícita uma solução inteiramente diversa daquela preconizada pelos partidários da reforma agrária. Se a estrutura agrária brasileira sempre teve uma "configuração capitalista", por que revolucioná-la? Por que reformá-la? (Guimarães, 1963, p. 23)

Mais ainda,

a negação ou mesmo subestimação da substância feudal do latifundismo brasileiro retira da reforma agrária sua vinculação histórica, seu conteúdo dinâmico e revolucionário.

Esse conteúdo dinâmico e revolucionário, na presente etapa da vida brasileira, expressa-se pelo objetivo principal do movimento pela reforma agrária, que é o de extirpar e destruir, em nossa agricultura, as relações de produção do tipo feudal. (Guimarães, 1963, p. 34)

Em outros termos, percebe-se que

afirmar a feudalidade permitia demonstrar que a tarefa da remoção dos "restos feudais" - cujos efeitos ao longo do tempo por certo diminuíram de intensidade - tinha raízes históricas, encerrava nova lógica para uma economia mais progressista, e também se convertia em processo emancipatório para milhões de camponeses e trabalhadores rurais, cidadãos sob sursis dos constrangimentos extraeconômicos impostos pelo "monopólio da terra". (Santos, 1994, p. 54)

Dessa forma, para o autor, a reminiscência "feudal" brasileira traduzia-se no monopólio da propriedade da terra. Assim, enfatiza a terra como a principal força produtiva, ou meio de produção, para o trabalho na agricultura brasileira. Nas palavras de Guimarães, “o monopólio feudal e colonial é a forma particular, específica, porque assumiu no Brasil a propriedade do principal e mais importante dos meios de produção na agricultura, isto é, a propriedade da terra” (Guimarães, 1963, p. 35).

Por essa ênfase, em sua principal obra, Quatro séculos de latifúndio, o economista analisa a formação econômica do Brasil através de "um fio condutor - a luta das classes pobres do campo pela conquista da terra" 
(Guimarães, 1963, p. 2). Como resultado, considera que a luta contra o monopólio da terra era o motor do desenvolvimento econômico nacional ${ }^{4}$.

Ainda nessa obra, Guimarães (1963) procura fundamentar teoricamente a preponderância da luta pela terra como motor da formação econômica do Brasil, tendo como paradigma histórico a Lei de Terras, de 18 de setembro de 1850. No capítuloVI, que intitula "Formação da pequena propriedade: intrusos e posseiros", o alagoano destaca que a Lei de Terras, ao bloquear o acesso à terra por pequenos agricultores familiares, havia generalizado a figura do posseiro.

Assim se constituía um amplo contingente de pequenos agricultores em permanente luta pela manutenção dos seus laços com a terra. Nos mais de quatro séculos da formação econômica da agricultura brasileira, destacava-se a importância da "figura do posseiro ou intruso, principalmente o posseiro ou intruso nativo, que enfrenta [...] o poder latifundiário, desde tempos mais recuados" (Guimarães, 1963, p. 113). Por isso, na formação econômica do Brasil, destacava-se a preponderância da luta pela terra da agricultura familiar "camponesa" contra o proprietário

4 Por causa da importância de o debate sobre a agricultura brasileira apresentar um suposto traço feudal, ou se ela fazia parte de um "capitalismo agrário", esses termos permanecem servindo de paradigma para inúmeras pesquisas até hoje (cf. Fernandes; Welch; Gonçalves, 2012, p. 16). O clássico Guimarães (1963) tem como base de sua caracterização feudal a definição de indústria moderna de Marx (1867, cap. XIII): a produção de máquinas por máquinas. Assim, o autor enfatiza as forças produtivas da agricultura brasileira que, pela ausência de uma indústria produtora de máquinas e bens de capital, classifica como não inteiramente "capitalistas". No debate internacional, a associação do "capitalismo" com a indústria de bens de capital é o cerne do pensamento nacional desenvolvimentista da CEPAL/ONU (Moreira, 1998, p. 340). Para a interpretação que enfatiza as forças produtivas, o "capitalismo" é capaz de adquirir força autônoma própria apenas com a indústria produtora de bens de capital. Somente com a emergência dessa indústria, o "capitalismo" consegue se libertar das forças produtivas da natureza, assim como suas classes e superstições, adquirindo força própria e incessável (cf. Malta et al., 2009, p. 6). Conferindo fortes preponderâncias às forças produtivas da agricultura brasileira, no pensamento de Guimarães (1963), as relações de produção do "capitalismo" industrial se encontravam restringidas pelas forças produtivas de natureza ainda "feudal-colonial" da economia essencialmente agrária brasileira. Essa natureza permitia a maioria esmagadora da população rural brasileira ainda não se encontrar totalmente divorciada da propriedade dos seus meios de produção de subsistência, e assim perpetuar tal modo "não capitalista" de reprodução da mão de obra (Guimarães, 1962). 
"feudal" de terras, no vocabulário da III Internacional Comunista mobilizado por Guimarães $(1963)^{5}$.

De acordo com Santos (2007a, p. 110), no mesmo capítulo sobre a formação da pequena propriedade na agricultura brasileira, o intelectual justifica essa vertente de reforma agrária, ainda hoje muito comum, com base na teoria da colonização sistemática de Wakefield, presente em $O$ capital, de Marx (1867, cap. XXV). Nas palavras do autor,

a colonização sistemática fundava-se no princípio que as terras virgens não deviam ser postas ao alcance das populações pobres por preços baixos, a elas acessíveis, porque, se assim acontecesse, os homens e mulheres mais capazes se transformariam em produtores independentes [como camponeses] em vez de se engajarem como trabalhadores nas propriedades latifundiárias. (Guimarães, 1963, p. 110-111)

Para Guimarães, "era exatamente essa a substância do pensamento wakefieldiano, do qual se impregnaram várias das disposições legais do Império, sem excluir a Lei das Terras promulgada em 1850" (Guimarães, 1963, p. 112). Segundo o autor, o mesmo modelo wakefieldiano de bloqueio ao acesso à terra teria sido aplicado nos tempos da colonização do país, assim como já nos tempos da República (cf. Guimarães, 1963, p. 53, 132). Em uma comparação internacional, "em vez de terra livre ao modo do Homestead Act, aqui se inventara mecanismos que conservavam a força de trabalho sob tutela" (Santos, 2007a, p. 88).

5 A III Internacional, fundada em 1928 (logo após a subida de Josef Stalin ao poder), pregava o que ficou conhecido como Revolução Democrático-Burguesa, ou o "modelo democrático burguês", para Mantega (1984). Por caminho "democrático", entenda-se a implementação de medidas de redistribuição de renda, em particular, a reforma agrária; e por "burguês" (ou "capitalista"), leia-se a produção industrial em larga escala. Para o modelo democrático burguês, a burguesia interessava-se pela reforma agrária, pois esta significava um crescimento da renda e consequente ampliação do mercado consumidor. Ao mesmo tempo, a reforma agrária também era capaz de varrer da economia política nacional as classes rentistas, que estrangulavam o desenvolvimento brasileiro. A crítica que se faz ao modelo democrático burguês é de duas ordens. Em primeiro lugar, a burguesia nacional é mais burguesa do que nacionalista, preferindo a manutenção de relações de dependência externas contra a "subversão" comunista. Em segundo lugar, a terra pode ser um interessante ativo financeiro, como reserva de valor. Como consequência, não existia necessariamente uma oposição inexorável entre classes agrárias e industriais, mas apenas entre segmentos dessas classes. 
Segundo o autor,

de tudo a quanto se propunha a lei de 1850 , somente medraram as determinações que dificultavam o acesso à terra por meio da posse ou da compra a baixo preço. Em suma, na sua execução prevaleceram unicamente os dispositivos que estavam em harmonia com o objetivo imediato da classe latifundiária semi-"feudal" e não inteiramente "capitalista": obrigar o imigrante a empregar sua força de trabalho nas grandes fazendas de café. (Guimarães, 1963, p. 135)

Na argumentação de Guimarães (1963), o alto preço da terra forçava o "camponês" a vender sua força de trabalho a baixo salário. A abundância da oferta de mão de obra rural fazia com que a agricultura dispensasse investimentos em tecnologias poupadoras de trabalho. Como resultado, o monopólio da terra desestimulava o desenvolvimento tecnológico nacional.

Em depoimento à Comissão de Reforma Agrária da Câmara dos Deputados, em 1962, o intelectual mostrava que, em última instância, o monopólio da terra, ao desestimular o desenvolvimento tecnológico nacional, podia levar a "uma crise estrutural no sistema agrário brasileiro, a qual só terá solução com uma reforma agrária que realize profundas mudanças no regime de propriedade da terra, que promova e acelere o desenvolvimento da agricultura e eleve o nível de vida dos trabalhadores agrícolas" (Guimarães, 1962, p. 57). Por essa razão, o "objetivo fundamental" da "reforma agrária democrática" era o de

destruir pela base um duplo sistema espoliativo e opressivo; romper e extirpar, simultaneamente, as relações semicoloniais de dependência ao imperialismo e os vínculos semifeudais de subordinação ao poder extraeconômico, político e "jurídico" da classe latifundiária. E tudo isso para libertar as forças produtivas e abrir novos caminhos à emancipação econômica e ao progresso de nosso país. (Guimarães, 1963, p. 38)

Em uma exposição simplificada, o raciocínio de Guimarães (1963) considera que a redistribuição da propriedade fundiária podia transferir parte da renda da terra do grande proprietário latifundiário a favor de pequenos proprietários familiares, e assim estimular o desenvolvimento econômico nacional. $\mathrm{O}$ alagoano possui como exemplo histórico de 
transformação na agricultura brasileira o caso do parcelamento das terras do Engenho da Galileia em favor das Ligas Camponesas, em 1959. Para o intelectual, dentre "várias das lutas vitoriosas dos posseiros pela validação de títulos de propriedade”, destacava-se, em especial, “a expropriação do Engenho da Galileia, em Pernambuco, alcançada depois de uma série de lutas a que não faltou a violência da polícia" (Guimarães, 1960, p. 81).

Esse exemplo histórico de reforma agrária mostrava que

as transformações realizadas, com a divisão de um latifúndio semifeudal entre camponeses [...], não se fez [sic] para conservar as velhas relações de produção existentes; desse ato resultou uma mudança na estrutura de propriedade que, de um latifúndio semifeudal, se transformou num certo número de propriedades camponesas. (Guimarães, 1960, p. 82)

Segundo Guimarães (1960, p. 91; 1963, p. 181), no caso da implementação de uma reforma agrária por meio do parcelamento de terras, a redistribuição da renda da terra levaria ao encarecimento relativo da mão de obra rural. Esse encarecimento da mão de obra incentivaria o desenvolvimento de tecnologias poupadoras de trabalho na agricultura. Portanto, a luta contra o monopólio da terra incentivaria o desenvolvimento tecnológico da agricultura brasileira.

\section{A estratégia alternativa de reforma agrária: a luta por melhores condições de trabalho}

Em linhas gerais, até o final da década de 1980 Caio Prado Jr. ainda era reconhecido como

um dos mais importantes pensadores brasileiros, um dos maiores nomes de nossa historiografia, cuja produção, iniciada na década de 30 , exerceu e continua a exercer uma influência marcante na vida intelectual e política do país.

Em Caio Prado a história surge com toda a força e dinamismo de uma atividade que, voltada para o conhecimento do passado, pode servir para instrumentalizar uma ação transformadora do presente, alterando, por conseguinte, a direção do porvir. (Freitas Filho, 1988, p. 9) 
Enquanto muitos autores da época mobilizavam um modelo teórico já pronto e procuravam justificá-lo para a prática política do partido no Brasil, Caio Prado Jr., ao contrário, primeiro investiga a singularidade da formação econômica da agricultura brasileira, para só então sugerir estratégias de luta no campo. Com base nesses estudos, nos debates sobre a reforma agrária travados no interior do PCB, Prado Jr.

vê [na vertente de Alberto Passos Guimarães] uma das muitas transposições mecanicistas feitas da Europa para o Brasil de situações sem real equivalência. Caio deseja a reforma agrária para elevar o nível de vida do povo, mas rejeita as fórmulas simples de exclusiva partilha da terra, sem mais complementos. (Iglésias, 1982, p. 38)

Em uma visão panorâmica,

o cerne das teses de Caio Prado é o ataque às relações sociais fundiárias e de trabalho no meio rural brasileiro. Estas relações impõem condições sub-humanas de vida a maior parte da população rural brasileira. Estas mesmas relações são vistas na obra de Alberto Passos Guimarães - "Quatro Séculos de Latifúndio" - como corroboração de sua tese de "restos feudais" na agricultura brasileira. Estes autores divergem em suas teses sobre a Questão Agrária e ainda preveem distintos enfoques da reforma agrária. (Delgado, 2010, p. 83)

Em sua principal obra, Formação do Brasil contemporâneo, no capítulo "Organização social", o historiador considera que a agricultura exercida com base na mão de obra familiar "camponesa", orientada para o mercado interno, era uma atividade econômica "sem classe bem definida" na formação econômica brasileira (Prado Jr., 1942, p. 300). Para o historiador,

o que no Brasil constitui propriamente economia camponesa (a exploração parcelária e individual do pequeno produtor camponês que trabalha por conta própria e como empresário da produção, em terras suas ou arrendadas), isto representa via de regra um setor residual da nossa economia agrária. (Prado Jr., 1966, p. 162)

Em Caminha (2007) se detalha a interpretação de Prado Jr. (1942) 
sobre o papel desse "elemento mal definido" e "residual", que "vai avultando com o tempo" - e que poderia se chamar de uma agricultura familiar "camponesa" - na formação econômica do Brasil. O importante é registrar, como faz Ricupero, que Prado Jr. (1942, 1966) considera que, nessa condição "mal definida" e "residual" na formação econômica do Brasil contemporâneo,"se encontrariam tanto atividades econômicas voltadas para o mercado interno, como a pecuária e a produção de determinados gêneros agrícolas (a mandioca, por exemplo), como toda uma multidão de situações de difícil classificação ou inclassificáveis" (Ricupero, 2012, p. 25).

No seu opúsculo A Revolução Brasileira, o historiador considera que uma vertente de política de reforma agrária com base na luta pela terra (mesmo que organizada em ligas “camponesas"), por não estar assentada em uma classe bem definida na formação econômica do Brasil contemporâneo, é uma “agitação estéril”. A vertente de reforma agrária com base na luta pela terra "camponesa", por não possuir organicidade na economia brasileira, levaria a reações mais que desproporcionais das classes conservadoras, como no Golpe de 1964 (Prado Jr., 1966, cap. II).

Isso porque, no capítulo "Sentido da colonização" da Formação do Brasil contemporâneo, o historiador já mostrava que a singularidade da formação econômica brasileira era que sua atividade preponderante, e com classes "nitidamente definidas", situava-se na agricultura patronal, orientada para o mercado externo, com base no emprego em larga escala de trabalhadores (Prado Jr., 1942, p. 289). Nas palavras do historiador,

aquilo que essencial e fundamentalmente forma esta nossa economia agrária, no passado como ainda no presente, é a grande exploração rural em que se conjugam, em sistema, a grande propriedade fundiária com o trabalho coletivo e em cooperação e conjunto de numerosos trabalhadores. (Prado Jr., 1966, p. 163)

Em suma, ao longo dos seus estudos sobre a singularidade das questões da agricultura brasileira, Prado Jr. procura identificar qual era "um dos principais obstáculos opostos à marcha construtiva da reforma agrária entre nós" (Prado Jr., 1963, p. 257). Para o autor, o maior e principal obstáculo era que 
não somente a subdivisão da propriedade fundiária está longe de constituir em todos os casos, e mesmo nos principais, o caminho acertado e mais fácil e seguro para a reforma agrária, como essa própria subdivisão, quando se recomenda, será enormemente facilitada e frequentemente até possibilitada pela efetiva aplicação preliminar de uma legislação reguladora das relações de trabalho e emprego rural, e protetora do trabalhador. (Prado Jr., 1963, p. 257)

De acordo com Prado Jr. (1963), em razão da especial preponderância da agricultura patronal do "agronegócio" na formação econômica do Brasil contemporâneo, a vertente de reforma agrária com base na luta por trabalho, organizando sindicatos nas grandes plantações de exportação, levava à acumulação de vitórias progressivas no decurso singular da Revolução Brasileira. Por essa virtude, "Caio Prado Jr. irá propor, como eixo reivindicatório, não propriamente a reforma agrária de tipo camponês, associável ao diagnóstico feudalista, mas melhorias econômicas, emprego, sobretudo a generalização da lei trabalhista" (Santos, 1994, p. 57).

Desse modo, Prado Jr. defende uma vertente de política de reforma agrária que busca assegurar direitos e garantias no mundo do trabalho. Por exemplo, a livre organização sindical e a previdência rural, melhores condições de trabalho na agricultura e, em especial, a regulamentação das relações de trabalho na agricultura (em específico, com a extensão da legislação sindical-trabalhista - a Consolidação das Leis do Trabalho - CLT - para a agricultura, bem como, dos Institutos de Aposentadorias e Pensões - IAPs), além da abolição do cambão (a obrigação de moradores trabalharem nas fazendas do patrão), da "moradia de condição" etc. ${ }^{6}$.

6 A reforma agrária sindicalista é sustentada por Prado Jr. (1942), conferindo forte preponderância às relações de produção da agricultura brasileira, que considera parte integrante da reprodução do capital mercantil, mostrada no livro II de O capital, de Marx (1883, cap. IV). Para Prado Jr. (1942), a relação de produção predominante na agricultura brasileira já era típica do "capitalismo", ainda que em sua forma mercantil. Isso porque as relações de produção do trabalhador brasileiro já o haviam divorciado dos seus meios de produção, primeiro, com o escravagismo e, posteriormente, com a restrição da agricultura familiar "camponesa" aos estados da região Sul do país (Prado Jr., 1946). A continuação do debate sobre se a agricultura brasileira era ou não "capitalista" leva à discussão sobre as formas de remuneração da mão de obra (se em dinheiro, produto ou serviço), especificamente no caso das relações de trabalho da parceria. Prado Jr. (1963) leva às ultimas consequências a afirmativa de que "o 
Por meio da vertente de reforma agrária com prioridade na luta por trabalho,

Caio Prado interpela o PCB a partir de seu pensamento agrário que confere protagonismo, no processo de uma revolução nacional, à mobilização do tipo trabalhista no mundo rural. Como ponto de partida do historiador, Santos [2007a] destaca a sua interpretação do Brasil como marco intelectual que fornece o fundamento para a proposta caiopradiana de uma reforma agrária não camponesa, ou seja, liderada por assalariados e semiassalariados organizados em sindicatos. O diagnóstico do intelectual paulista considera o padrão de nosso processo de modernização conferindo debilidade às forças progressistas populares, dentre elas, os camponeses, por ele considerados grupos agrários menos importantes à "revolução brasileira". (Melo, 2008, p. 178)

Isto é, na interpretação de Prado Jr. (1942) sobre a formação econômica do Brasil contemporâneo, a economia camponesa é um resíduo, sem classe bem definida; e a agricultura patronal é a atividade econômica preponderante, com classes nitidamente definidas. Como consequência dessa singularidade brasileira, considera que

não é pela ocupação individual e parcelária dessa terra onde hoje trabalham coletivamente entrosados no sistema da grande exploração, que aqueles trabalhadores procuram solucionar seus problemas de vida e superar as miseráveis condições de existência que são as suas. Nos maiores e principais

indicador essencial do capitalismo na agricultura é o trabalho assalariado" (Lenin, 1918, p. 63). Assim, Prado Jr. (1963) observa que as plantações em larga escala da agricultura patronal empregam trabalhadores rurais, que designa como "semiassalariados agrícolas" (o "semi” é razão de parte do pagamento ser efetuada em bens agrícolas, e não em cruzeiros). Ainda assim, considera que a remuneração em bens é racional para o trabalhador rural diante de uma economia inflacionária. Martins (1978) destaca ainda que a parceria não pode ser classificada como inteiramente "capitalista", já que o trabalhador não percebe que vende sua força de trabalho, mas, sim, seus produtos e bens. Por tudo isso, Kageyama et al. (1990) classificam o "complexo rural" de atividades da agricultura brasileira da década de 1950 como pertencente ao capital mercantil. Assim, contrapõem o capital mercantil agrário ao capital produtivo (industrial, ou de uma agricultura industrializada) e ao capital dinheiro (financeiro), assim como, da economia mercantil simples (ou camponesa, em que o trabalhador é, ele próprio, o proprietário dos meios de produção), exposta na primeira parte de O capital, de Marx (1867, cap. I-III). 
setores da agropecuária brasileira, naqueles que constituem em conjunto o cerne da economia agrária do país [...], os trabalhadores, como empregados que são da grande exploração, simples vendedores de força de trabalho, portanto, e não "camponeses", no sentido próprio, aquilo pelo que aspiram e reivindicam [sic], o sentido principal de sua luta é a obtenção de melhores condições de trabalho e emprego. (Prado Jr., 1966, p. 166)

Com base nessa sua interpretação sobre a singularidade da formação econômica do Brasil,

Caio Prado Jr. aponta, em 1963, para a ausência das esquerdas no debate da questão da legislação rural-trabalhista, solenemente ignorada pelos reformadores agrários daquele Brasil tão cheio de esperanças mas tão carente de estudos de profundidade sobre o problema das relações sociais no campo. (Penna, 2008, p. 142)

Apesar da pouca atenção conferida pelo seu PCB à tramitação do Estatuto do Trabalhador Rural, em 1963, o historiador considera que a implementação de uma vertente de reforma agrária com base nesse estatuto "será, podemos dizer, uma verdadeira complementação da lei que aboliu a escravidão em 1888” (Prado Jr., 1963, p. 251). Desse modo, justifica a vertente alternativa de reforma agrária tendo como paradigma histórico a Lei Áurea, de 13 de maio de 1888.

Assim, leva às últimas consequências a teoria do valor-trabalho, presente em $O$ capital, de Marx (1867, seção 1). Essa teoria considera que a renda da terra (como a do capital) é advinda do monopólio de classe, e que o trabalho é o único gerador de valor econômico.

Desse modo, Prado Jr., com base especialmente na teoria do valor-trabalho de Marx, destaca uma associação direta entre o custo da mão de obra e o desenvolvimento tecnológico da economia. Nas palavras do historiador marxista,

os baixos padrões de produtividade e ínfimo nível tecnológico que predominam na generalidade da agropecuária brasileira se devem em primeiro e principal lugar ao baixo custo da mão de obra. É somente graças a isso que boa parte das grandes explorações rurais brasileiras, apesar dos rotineiros processos de produção que empregam, conseguem se manter e são rentáveis. Isso porque, assegurada a rentabilidade da empresa mercê do baixo custo 
da mão de obra empregada, dispensam-se aperfeiçoamentos tecnológicos, maiores atenções na condução das atividades produtivas e intensificação na produção. (Prado Jr., 1963, p. 262)

Em uma exposição simplificada, o raciocínio de Prado Jr. (1963) considera que a organização de sindicatos de trabalhadores rurais, na agricultura patronal, podia levar à elevação do custo da mão de obra; esta incentivaria o desenvolvimento de tecnologias poupadoras de trabalho na agricultura brasileira, ao mesmo tempo em que promoveria a ampliação do seu próprio mercado consumidor interno. Nas palavras de Prado Jr., "a valorização do trabalhador estimulará e forçará a melhoria da produtividade pelo emprego de processos e técnicas de mais alto nível e rendimento" (Prado Jr., 1963, p. 262). Portanto, a vertente de reforma agrária com base na luta sindicalista por melhores condições de trabalho seria uma estratégia de reforma agrária alternativa à vertente usual de reforma agrária centrada na luta "camponesa" pela terra.

Assim, de tudo o exposto ao longo deste artigo (e resumido no Quadro-síntese apresentado no Apêndice), é possível constatar que, muito embora Guimarães (1963) não negue a teoria valor-trabalho, Prado Jr. (1963) mobiliza esta de uma forma um tanto diferente. Conforme analisado no tópico anterior, enquanto o primeiro autor considerava que a relação entre o valor do trabalho e o progresso tecnológico era mediada pela renda da terra, no presente tópico percebe-se que o segundo apresenta uma relação direta entre as mesmas variáveis, sem que para isso necessite utilizar de mediações ad hoc. Por isso, Prado Jr. não precisa utilizar-se de malabarismos intelectuais para poder concluir sua argumentação, desenvolvida em toda sua completude em torno da teoria do valor-trabalho, já consistente e concisa em si.

\section{A síntese de Guimarães: a "estratégia sindical- camponesa" do PCB}

O debate entre as vertentes de reforma agrária de Caio Prado Jr. e Alberto Passos Guimarães no interior do PCB torna possível perceber que 
existiam diversas propostas de reforma agrária, então entendida muito amplamente como qualquer ação social, assistencial ou econômica aos agricultores, fossem eles trabalhadores sem terra, pequenos, médios ou grandes proprietários. Mas para a esquerda nacionalista a reforma agrária tinha um sentido muito específico, e, dentre as inúmeras propostas sobre a questão, duas eram consideradas inadiáveis: a criação do regime jurídico do trabalhador rural e a reforma agrária distributiva de terras. (Moreira, 1998, p. 351)

Em um panorama geral, a vertente usual de reforma podia se aplicar a economias agrárias caracterizadas pela agricultura com base na mão de obra familiar, com pequenos e médios cultivos. E a vertente alternativa de reforma aplicava-se para economias agrárias caracterizadas pela agricultura patronal, de plantações em larga escala ${ }^{7}$.

Em termos históricos, uma reforma é própria para as colônias de povoamento; e outra, para as de exploração. Em um esquema geográfico, no caso brasileiro, uma aplica-se para a região Nordeste e o Brasil profundo; outra, para o Rio Grande do Sul e Santa Catarina.

Assim, em virtude da diferença entre uma agricultura cuja estrutura econômica predomina a agricultura familiar, ou a agricultura patronal, podem-se aplicar distintas vertentes de reforma agrária: uma centrada nas relações de trabalho e outra, nas relações de propriedade da terra. Na terminologia de Mao Tsé-Tung (1937), trata-se de encontrar qual é a "contradição principal” da agricultura brasileira: entre agricultores proprietários e não proprietários de terras, ou entre monopolizadores das condições de trabalho e despossuídos rurais.

No debate internacional sobre a questão de uma reforma agrária sindical ou camponesa, é significativo que o Dicionário do pensamento marxista, na sua definição de "campesinato", considera este um "termo que geralmente designa o conjunto daqueles que trabalham na terra e possuem seus meios de produção" (Bottomore, 1983, p. 42). De forma ainda mais precisa, no Dicionário do pensamento social do século $X X$, o

7 Na teoria caiopradiana, o fato dessas grandes plantações serem orientadas para a exportação é mera consequência das vantagens comparativas obtidas com o baixo custo da mão de obra na agricultura brasileira. Assim, uma reforma agrária sindical-trabalhista nessas grandes plantações também teria como efeito a reorientação da agricultura nacional para a produção de gêneros agrícolas de consumo interno. 
"campesinato" é definido como o grupo de "pequenos produtores agrícolas que, com a ajuda de equipamentos simples e o trabalho de suas famílias, produzem na maior parte para seu próprio consumo" (Outhwaite; Bottomore, 1996, p. 54-55).

Ao mesmo tempo, esses dicionários especializados enfatizam que se deve "distinguir entre camponeses e outros trabalhadores agrícolas não assalariados" (Bottomore, 1983). Em específico, os pequenos produtores rurais distinguem-se de "trabalhadores agrícolas assalariados (e também os camponeses-operários, que adotam uma divisão do trabalho do tipo 'o homem na cidade, o resto da família na terra')", assim como de "camponeses sem aldeia - como, por exemplo, alguns favelados das fronteiras agrícolas latino-americanas e os 'gaúchos"' (Outhwaite; Bottomore, 1996 , p. 54-55) ${ }^{8}$.

8 Na história do pensamento marxista internacional, a controvérsia entre Prado Jr. (1963) e Guimarães (1963) sobre o ator social preponderante na agricultura - trabalhador rural ou camponês, que pode ou não sustentar diferentes vertentes de reforma agrária, por trabalho ou por terra - encontra correspondência no debate original entre Lenin e Kautsky, respectivamente. Kautsky (1900) se baseia no primeiro capítulo do Manifesto, de Marx e Engels (1848, p. 33), que trata da odisseia e do potencial revolucionário da burguesia. Marx e Engels consideram que, na etapa histórica ainda anterior ao predomínio da burguesia, quando os proletários lutam contra os proprietários fundiários, "não combatem os seus inimigos, mas os inimigos dos seus inimigos, os restos da monarquia absoluta, os proprietários territoriais, os burgueses não industriais, a pequena burguesia" (Marx; Engels, 1848, p. 43). Por isso, "Kautsky propõe enfaticamente a superioridade da grande exploração", segundo Cardim (1978, p. vii). Assim, Kautsky enfatiza que "somente o modo de produção capitalista cria as condições preliminares para a grande fazenda cooperativa, enquanto não apenas produz uma classe de operários que estão excluídos da propriedade privada dos meios de produção, como também converte em social o próprio processo de produção e gera e agrava o antagonismo de classe entre os capitalistas e seus operários assalariados, antagonismo que impulsiona estes a se esforçarem para substituir a propriedade capitalista pela propriedade social dos meios de produção” (Kautsky, 1900, p. 151). Mais importante, Kautsky (apud Lenin, 1918, p. 54-55) não distingue o pequeno agricultor familiar "camponês" do trabalhador rural semiassalariado, empregado na agricultura patronal. Assim, Kautsky considera que, "do ponto de vista socialista, o mais racional teria sido transformar as grandes empresas em propriedade do Estado e ceder aos camponeses, que até então estavam ocupados nelas como operários assalariados, o cultivo dos grandes domínios sob a forma de cooperativas. [...] Outra solução podia ter sido a transformação da grande propriedade agrária em propriedade do Estado, com a sua divisão em pequenas parcelas entregues em arrendamento aos camponeses com pouca terra. Desta maneira ter-se-ia realizado algo do socialismo" (Kautsky, apud Lenin, 1918, p. 54-55). De seu lado, Lenin distingue o trabalhador rural do agricultor familiar, 
No caso específico da história econômica da agricultura brasileira,

dificilmente se encontra no Brasil a dependência servil do pequeno agricultor ao dono da terra, da forma descrita e dramatizada por muitos. A intensa mobilidade dos assalariados e pequenos agricultores em busca de melhores salários e condições de trabalho é uma prova dessa nova afirmativa. (Paiva, 1968, p. 77)

Segundo Saint Hilaire, a principal característica dos "homens livres e pobres" do Brasil era a sua "extrema mobilidade": "emigrava-se às vezes por nada, e com simples e vagas esperanças de outras perspectivas" (apud Prado Jr., 1942, p. 67). Talvez por isso, em uma obra de ficção coberta pelo realismo regional nordestino, Vidas secas, de Graciliano Ramos, o personagem Fabiano considere que

a sina dele era correr mundo, andar para cima e para baixo, à toa, como judeu errante. Um vagabundo empurrado pela seca. Achava-se ali de passagem, era hóspede. Sim senhor, hóspede que demorava demais, tomava amizade à casa, ao curral, ao chiqueiro das cabras, ao juazeiro que os [sic] tinha abrigado uma noite. (Ramos, 1938, p. 8)

porém ressalta que "na Rússia há operários agrícolas assalariados, mas são poucos", e pergunta "Por que é que você [Kautsky], douto economista, não citou dados que conhece perfeitamente e que figuram na mesma estatística alemã de 1907 sobre o trabalho assalariado na agricultura?"; além do mais, o autor considera que "o pequeno produtor camponês vacila inevitavelmente entre o proletariado e a burguesia", uma "verdade marxista confirmada por toda a história moderna da Europa" (Lenin, 1918, p. 55,33,47). No mesmo capítulo I do Manifesto, é célebre a passagem sobre a "idiotia [ou estreiteza] da vida rural" (sobre o significado clássico do termo grego "idiotes", ver Hobsbawm, 1997). Lenin considera que, em economias predominantemente agrárias, “em países como a Rússia, a classe operária sofre não tanto do capitalismo como da insuficiência do desenvolvimento do capitalismo" (Lenin, 1905, p. 406). Por isso, o autor sublinha o capítulo 2 do Manifesto, em que Marx e Engels (1848) destacam a importância do partido dos trabalhadores. Para Lenin, o partido dos trabalhadores tem o papel de conduzir a Revolução Operária, em aliança com os camponeses, para "levar até às ultimas consequências" a Revolução Democrático-Burguesa - que a própria burguesia hesitava em levar a cabo (Lenin, 1905, p. 399). Dessa maneira, "foram precisamente os bolcheviques, e só os bolcheviques, que, só em consequência da vitória da revolução proletária, ajudaram os camponeses a levar verdadeiramente a revolução democrático-burguesa. E só assim fizeram o máximo para facilitar e apressar a passagem à revolução socialista” (Lenin, 1918, p. 59), 
De acordo com José de Souza Martins, a história do "camponês brasileiro é [de] desenraizado, é [de] migrante, é [de] itinerante. A história dos camponeses-posseiros é uma história de perambulação. A história dos camponeses-proprietários do sul é uma história de migrações". Por isso, o "nomadismo do camponês brasileiro foi e ainda é muito característico. Às vezes, nomadismo restrito a uma área de perambulação na realização da agricultura de roça; às vezes, o nomadismo mais extenso, na tentativa de encontrar um novo lugar" (Martins, 1981, p. 17, 112).

Finalmente, Sérgio Buarque de Holanda nos lembra que

a distinção entre o meio urbano e a "fazenda" constitui no Brasil, e pode dizer-se que em toda a América, o verdadeiro correspondente da distinção clássica e tipicamente europeia entre a cidade e a aldeia. Salvo muito raras exceções, a própria palavra "aldeia", no seu sentido mais corrente, assim como a palavra "camponês", indicando o homem radicado ao seu rincão de origem através de inúmeras [e imemoriais] gerações, não correspondem no Novo Mundo a nenhuma realidade. É por isso, com o crescimento dos núcleos urbanos, o processo de absorção das populações rurais encontra aqui menores resistências do que, por exemplo, nos países europeus. (Holanda, 1936, p. 56-57)

Ao longo do debate teórico com Prado Jr. e alguns desses outros autores clássicos, assim como os relatos na imprensa comunista sobre a experiência empírica de luta no campo do PCB, nas décadas de 1950 e 1960, com a Guerrilha de Porecatu (no oeste do Paraná), na organização de posseiros em Trombas e Formoso (em Goiás) e na Liga de Ipatinga (atualmente, bairro de Recife) em uma de suas intervenções nos congressos do Partido Comunista, Guimarães (1960) terminaria reconhecendo que, efetivamente, a luta por trabalho, organizando sindicatos de trabalhadores rurais na agricultura patronal, mostrava-se "mais suscetível de organização”. Já a luta pela terra, organizando a agricultura familiar "camponesa", era de "débil organização" no vocabulário leninista de Guimarães (1960).

A mudança no pensamento de Guimarães ocorreria com seu reconhecimento do "caráter expansivo do sindicalismo, neste ponto concordando (parcialmente) com Caio Prado. Era difícil ignorar na discussão 
congressual de 1960 o tipo de associativismo no qual o historiador vinha insistindo há muitos anos" (Santos, 2007a, p. 85).

Se esse é o percurso, tortuoso, de Alberto Passos Guimarães, pode-se afirmar que ele terá consequência no interior do seu partido, e/ou espelhará o esforço pela "nova política". Através dele caminhava-se no PCB para uma nova compreensão, segundo a qual os camponeses não constituiriam mais a "questão central da revolução", mas seriam uma dentre as classes [...] consideradas estratégicas para a estruturação de um processo reformador a se conformar no plano da política com muitas mediações, descontinuidades e gradualismo. (Santos, 1994, p. 61-62)

A partir desse reconhecimento, o "intelectual orgânico" comunista sugere que, uma vez que o PCB conquistasse amplas bases de apoio entre os sindicatos de trabalhadores rurais, se poderia então chegar à luta pela terra "camponesa". No vocabulário do comunista, a "revolução agrária não camponesa", iniciada como uma luta sindicalista por trabalho, no decurso da luta de classes no campo brasileiro poderia então se transformar em uma "revolução camponesa" em torno da luta pela terra propriamente dita.

Dessa forma, nos debates travados no interior do PCB, Guimarães (1960) acaba reconhecendo a preponderância da vertente sindical de luta por trabalho, por meio de uma reforma agrária "não camponesa". Apesar desse reconhecimento, considera que, "à medida que os camponeses forem levados a participar do movimento agrário, conduzidos pelo proletariado em aliança com este, a reforma agrária não camponesa (nos seus inícios) se transformará numa reforma agrária camponesa" (Guimarães, 1960, p. 77).

Para o alagoano,

do ponto de vista da construção da aliança operário-camponesa, a frente da luta de classe dos assalariados e semiassalariados agrícolas (que muito frequentemente aliam à condição de assalariados a condição de camponeses) tem especial preponderância sobre as demais. Por intermédio dessa frente será possível montar as correias de transmissão que irão ligar o proletariado e o movimento democrático das cidades aos camponeses e ao movimento democrático do campo. (Guimarães, 1960, p. 86) 
De acordo com Santos, com a formulação de uma "aliança sindical-camponesa" na agricultura brasileira, Guimarães (1960) discorda da proposta "caiopradiana de revolução não camponesa protagonizada 'do começo ao fim' do processo revolucionário por grupos 'não camponeses" de trabalhadores rurais organizados em sindicatos agrícolas; assim, "diferentemente de Caio Prado Jr., nosso ensaísta não leva às últimas consequências a ideia de revolução agrária não camponesa" do início ao fim (Santos, 2007a, p. 74).

Ainda para Santos, Guimarães (1960) reconhece que a formação econômica da agricultura brasileira se caracterizava por ter um "campesinato recente, de movimento camponês atrasado"; por isso, "pensa uma 'revolução agrária' que poderia iniciar-se a partir de uma mobilização de assalariados e semiassalariados agrícolas (ou, repetindo os termos das Teses [do congresso comunista]: ter suas 'bases iniciais' nos sindicatos que o PCB organizava com vistas a alcançar o campesinato)" (Santos, 2007a, p. 75).

Não é demais citar uma dessas teses do V Congresso do PCB, de 1960. Em especial, a em que se lê que,

a fim de impulsionar a organização das massas do campo, é necessário atribuir uma atenção primordial aos assalariados e semiassalariados agrícolas. Em virtude da sua condição social de proletários ou semiproletários, como também do seu grau de concentração, os assalariados rurais são mais suscetíveis de organizarem-se em sindicatos que podem constituir as bases iniciais para a mobilização das massas camponeses. (PCB, 1960, apud Santos, 2007a, p. 76)

Essa passagem das teses doV Congresso é de especial relevo no debate sobre as vertentes de luta pela reforma agrária a serem seguidas pelo PCB nas décadas de 1950 e 1960. Isso porque ela expressa, em primeiro lugar, a fórmula de Guimarães $(1960$, p. 86) sobre a reforma agrária "não camponesa", que, iniciada como uma luta por trabalho e emprego, se transformaria em uma reforma agrária “camponesa” em torno da luta pela terra9.

Cabe notar que, para Prado Jr., aquela mesma passagem das teses do V Congresso "constituiu reconhecimento implícito, mas sem dúvida bem caracterizado, de que a revolução no campo não tem sua mola mestra em nenhuma luta antifeudal, e não se dirige contra nenhum resto semifeudal" ou "latifundista" (Prado Jr., 1966, p. 172). 
Portanto, é possível concluir que o "intelectual orgânico" Alberto Passos Guimarães (1960), ao longo do debate teórico com Caio Prado Jr. e das experiências empíricas do partido, evocaria uma mudança na estratégia de luta pela reforma agrária seguida pelo PCB.

A consequência principal dessa mudança na estratégia de luta política do partido seria que - embora existissem diferenças axiais entre as vertentes de reforma agrária de Alberto Passos Guimarães e de Caio Prado Jr. - o debate teórico e a experiência empírica do PCB apresentariam, em seu término, uma convergência. Essa convergência em torno da "nova política" do PCB se expressaria na preponderância da vertente de luta pela reforma agrária em torno da organização de sindicatos de trabalhadores rurais - e, assim, inserida na defesa do regime democrático "burguês" brasileiro ao longo das décadas de 1960 e 1970 (Ribeiro, 1975).

Em resumo, de tudo o exposto neste artigo, pode-se dizer que a vertente usual de reforma agrária, aqui representada por Guimarães (1963), priorizava a luta pela reforma nas relações de propriedade da terra rural, por meio da associação de agricultores "camponeses". Já a vertente alternativa, representada por Prado Jr. (1942), priorizava a luta pela reforma nas relações de trabalho rural, por meio da organização de sindicatos de trabalhadores da agricultura patronal. Em conjunto, o debate teórico e a experiência empírica das lutas priorizadas por essas duas vertentes de reforma agrária terminariam originando o que pode se denominar por "estratégia sindical-camponesa" seguida pelo PCB na década de 1960 (Santos, 2002). 


\section{Apêndice}

Quadro-síntese: o debate sobre a reforma agrária entre Guimarães e Prado Jr. no PCB

\begin{tabular}{|c|c|c|}
\hline AUTOR AGRARISTA & Alberto Passos Guimarães & Caio Prado Jr. \\
\hline $\begin{array}{l}\text { Ventente de luta } \\
\text { agrária }\end{array}$ & Camponesa & Sindical \\
\hline $\begin{array}{l}\text { Ênfase } \\
\text { interpretativa }\end{array}$ & $\begin{array}{l}\text { Forças produtivas "não } \\
\text { capitalistas" }\end{array}$ & $\begin{array}{l}\text { Relações de produção do capital } \\
\text { mercantil }\end{array}$ \\
\hline Orientação política & $\begin{array}{l}\text { Luta "antifeudal" com a } \\
\text { "revolução burguesa" da III } \\
\text { Internacional Comunista, de } 1928\end{array}$ & $\begin{array}{l}\text { Ausência de "classe bem definida" } \\
\text { em torno da luta pela terra } \\
\text { "camponesa" }\end{array}$ \\
\hline $\begin{array}{l}\text { Estratégia de luta } \\
\text { agrária }\end{array}$ & Terra & Trabalho \\
\hline Paradigma histórico & Lei de Terras (1850) & Lei Áurea (1888) \\
\hline Paradigma teórico & $\begin{array}{l}\text { Teoria da colonização sistemática } \\
\text { de Wakefield, em Marx (1867, } \\
\text { Cap. 25) }\end{array}$ & $\begin{array}{l}\text { Teoria do valor-trabalho de } \\
\text { Marx }(1867, \text { Seção 1) }\end{array}$ \\
\hline $\begin{array}{l}\text { Exemplo histórico } \\
\text { de política de } \\
\text { reforma agrária }\end{array}$ & $\begin{array}{l}\text { Parcelamento das terras do } \\
\text { Engenho da Galileia (1959): } \\
\text { "mudança na estrutura de } \\
\text { propriedade que, de um latifúndio } \\
\text { semifeudal, se transformou num certo } \\
\text { número de propriedades camponesas" } \\
\text { (Guimarães, 1960, p. 82) }\end{array}$ & $\begin{array}{l}\text { Estatuto do Trabalhador } \\
\text { Rural (1963): “uma verdadeira } \\
\text { complementação da lei que aboliu a } \\
\text { escravidão em 1888." (Prado Jr., } \\
\text { 1963, p. 151) }\end{array}$ \\
\hline $\begin{array}{l}\text { Lócus de luta } \\
\text { agrária }\end{array}$ & $\begin{array}{l}\text { Cooperativas de posseiros ou } \\
\text { "camponeses" da agricultura } \\
\text { familiar }\end{array}$ & $\begin{array}{l}\text { Sindicatos de trabalhadores rurais } \\
\text { na agricultura patronal }\end{array}$ \\
\hline Síntese & \multicolumn{2}{|l|}{ Estratégia sindical-camponesa } \\
\hline
\end{tabular}

Fonte: elaboração própria

\section{Referências bibliográficas}

BARROS, Diego. Alberto Passos Guimarães: um alagoano que lutou pela justiça social, 2008. Disponível em <http://www.iteral.al.gov.br/sala-de-imprensa/noticias/2008/12/a-um-passo-de-guimaraes>. Acesso em 24/11/2018.

BOTTOMORE, Tom (org.). Dicionário do pensamento marxista. Rio de Janeiro: Jorge Zahar, 2001 (1983).

CAMINHA, Pedro Vilela. A presença do agregado na Formação do Brasil contemporâneo de Caio Prado Junior. Revista de Economia Política e História Econômica. São Paulo, GEEPHE, v. 10, p. 48-60, 2007. 
CAMINHA, Pedro Vilela. A questão agrária em três autores brasileiros. Revista da Associação Brasileira de Reforma Agrária. Brasília, v. 12, p. 181-183, 2008.

CAMINHA, Pedro Vilela. Reforma agrária e contrarreforma: a modernização agrícola a partir de JK. Rio de Janeiro: Curso de Pós-Graduação em Desenvolvimento, Agricultura e Sociedade, Universidade Federal Rural do Rio de Janeiro (CPDA-UFRRJ), 2009 (Dissertação de Mestrado).

CARDIM, Fernando José. Agricultura e questão agrária no pensamento econômico brasileiro (1950-1970). Campinas: Instituto de Filosofia e Ciências Humanas, Universidade Estadual de Campinas, 1978, mimeo. (Dissertação de Mestrado).

COSTA, EmíliaViotti. Da Monarquia à República: momentos decisivos. São Paulo: UNESP, 2007.

COSTA, Luiz Flávio Carvalho. Sindicalismo rural brasileiro em construção. Rio de Janeiro: Forense Universitária, 1996 (1991).

DELGADO, Guilherme Costa. A questão agrária e o agronegócio no Brasil. In: CARTER, Miguel. Combatendo a desigualdade social: o MST e a reforma agrária no Brasil. São Paulo: UNESP, 2010.

DEVRIES, Jan. The Industrial Revolution and the industrious revolution. The Journal of Economic History. Cambridge University Press, v. 54, n. 2, p. 249-270, June 1994.

FERNANDES, Bernardo Mançano; WELCH, Clifford Andrew; GONÇALVES, Elienai Constantino. Políticas fundiárias no Brasil: uma análise geo-histórica da governança da terra no Brasil. Framing Debate Series. Roma, International Land Coalition, n. 2, 2012.

FERNANDES, Florestan. A revolução burguesa no Brasil: ensaio de interpretação sociológica. São Paulo: Zahar, 1974.

FREITAS FILHO, Almir Pita. A historiografia sobre a formação econômica do Brasil e a problemática do modo de produção escravista colonial: notas de aula. Rio de Janeiro: Faculdade de Economia e Administração, Universidade Federal do Rio de Janeiro, fev. 1988 (Texto Didático, n. 35).

GUIMARÃES, Alberto Passos. A questão agrária (declarações prestadas à Comissão de Reforma Agrária da Câmara dos Deputados). Boletim Geográfico. Rio de Janeiro, Conselho Nacional de Geografia, IBGE, ano XX, n. 166, p. 53-57, jan.-jun. 1962.

GUIMARÃES, Alberto Passos. Quatro séculos de latifúndio. 3. ed. Rio de Janeiro: Paz e Terra, 1977 (1963).

GUIMARÃES, Alberto Passos. A crise agrária. Rio de Janeiro: Paz e Terra, 1982 (1979) (Coleção O Mundo Hoje).

GUIMARÃES, Alberto Passos. As classes perigosas: banditismo rural e urbano. Rio de Janeiro: Graal, 1982.

GUIMARÃES, Alberto Passos. As três frentes da luta de classes no campo brasileiro. In: SANTOS, Raimundo. Questão agrária e política: autores pecebistas. Rio de Janeiro: EDUFRURALRJ, 1996 (1960), p. 75-93.

HOBSBAWM, Eric. Introdução ao Manifesto Comunista. Sobre história. São Paulo: Companhia das Letras, 2006 (1997). 
HOLANDA, Sérgio Buarque de. Raízes do Brasil. Rio de Janeiro: José Olympio, 1990 (1936).

IGLÉSIAS, Francisco (org.). Introdução: um historiador revolucionário. Caio Prado Junior: história. São Paulo: Ática, 1982.

KAGEYAMA, Ângela (coord.) et al. Agricultura e políticas públicas. Brasília: Instituto de Pesquisa Econômica Aplicada, 1990.

KAUTSKY, Karl. La cuestión agraria: análisis de las tendencias de la agricultura moderna y de la política agraria de la socialdemocracia. Buenos Aires: SigloVeintiuno, 1977 (1900).

LENIN,Vladimir. El programa agrario de la socialdemocracía, en la primera revolución rusa de 1905-1907. Moscú: Ediciones en Lenguas Extranjeras, 1949 (1905).

LENIN,Vladimir. Capitalismo e agricultura nos EUA: novos dados sobre as leis do desenvolvimento capitalista na agricultura. São Paulo: Brasil Debates, 1980 (1918). Disponível em <http://pcb.org.br/portal/docs/lenincapitalismoeagriculturaeua.pdf>. Acesso em 8/11/2018.

LINHARES, Maria Yedda; TEIXEIRA, Francisco Carlos. História da agricultura brasileira: combates e controvérsias. São Paulo: Brasiliense, 1981.

MALTA, Maria Mello de et al. A história do pensamento econômico brasileiro entre 1964 e 1989: um método para discussão. ANAIS DO XXXVII ENCONTRO NACIONAL DE ECONOMIA. Foz do Iguaçu: ANPEC, 2009.

MANTEGA, Guido. A economia política brasileira. Rio de Janeiro:Vozes, 1984.

MARTINS, José de Souza. O cativeiro da terra. São Paulo: Ciências Humanas, 1979 (1978).

MARTINS, José de Souza. Os camponeses e a política no Brasil: as lutas sociais no campo e seu lugar no processo político. São Paulo: Ciências Humanas, 1984 (1981).

MARX, Karl. O capital: crítica da economia política. Rio de Janeiro: Civilização Brasileira, 1968 (1867).

$M A R X$, Karl. O capital: crítica da economia política. Livro II. Org. Friedrich Engels. Rio de Janeiro: Civilização Brasileira, 1968 (1883).

MARX, Karl. O Dezoito Brumário de Louis Bonaparte. São Paulo: Abril Cultural, 1985 (1852).

MARX, Karl. Contribuição à crítica da economia política. São Paulo: Martins Fontes, 2003 (1859).

MARX, Karl; ENGELS, Friedrich. O manifesto do Partido Comunista. Rio de Janeiro: Paz e Terra, 1998 (1848) (Coleção Leitura).

MEDEIROS, Leonilde Servolo de. Lavradores, trabalhadores agrícolas, camponeses: os comunistas e a constituição de classes no campo. Campinas: Instituto de Filosofia e Ciências Humanas, Universidade Estadual de Campinas, 1995 (Tese de Doutorado).

MELO, Ana Amélia. Os agraristas políticos brasileiros. Pensamento Plural. Pelotas, n. 2, p. 177-180, jan.-jul. 2008.

MOITA, Guilherme Marinho; STROTOPASOLAS, Valmir Luiz. O agrarismo comunista brasileiro. Revista Sociologia Política. Curitiba, v. 16, n. 31, p. 219-222, nov. 2008.

MOREIRA,Vania Maria Losada. Nacionalismos e reforma agrária nos anos 50. Revista Brasileira de História. São Paulo,ANPHU/Humanitas, v. 18, n. 35, p. 329-360, 1998. 
MOTTA, Márcia (org.). Política agrária. Dicionário da terra. Rio de Janeiro: Civilização Brasileira, 2005.

OLIVEIRA, Ricardo. Caio Prado Júnior e Alberto Passos Guimarães: um debate interpretativo sobre a questão agrária nos anos 1960. Cadernos de História. Ouro Preto, Universidade Federal de Ouro Preto, ano 2, v. IV, n. 2, p. 120-129, 2007. Disponível em <www.ichs.ufop.br/cadernosdehistoria>. Acesso em 9/11/2018.

OUTHWAITE, William;BOTTOMORE,Tom. Dicionário do pensamento social do século XX. Rio de Janeiro: Zahar, 1996.

PAIVA, Ruy Miller. Apreciação geral sobre o comportamento da agricultura brasileira. Revista de Administração Pública, n. 3, p. 55-117, jan.-jun. 1969 (1968).

PENNA, Lincoln de Abreu. Revisitando a Revolução Brasileira. Revista de Estudos Sociedade e Agricultura. Rio de Janeiro, v. 16, n. 1, p. 139-142, 2008.

PRADO JR., Caio. História econômica do Brasil. São Paulo: Brasiliense, 1992 (1946).

PRADO JR., Caio. Formação do Brasil contemporâneo. São Paulo: Publifolha, 2000 (1942).

PRADO JR., Caio. O estatuto do trabalhador rural. In: SANTOS, Raimundo (org.). Caio Prado Jr: dissertações sobre a Revolução Brasileira. São Paulo: Brasiliense/ Fundação Astrojildo Pereira, 2007 (1963).

PRADO JR., Caio. A revolução agrária não camponesa. São Paulo: Brasiliense, 1987. In: SANTOS, Raimundo (org.). Caio Prado Jr: dissertações sobre a Revolução Brasileira. São Paulo: Brasiliense/Fundação Astrojildo Pereira, 2007 (1966).

RAMOS, Graciliano. Vidas secas. São Paulo: Martins, 1970 (1938).

RIBEIRO, Ivan de Otero. A agricultura e o capitalismo no Brasil. In: COUTINHO, Carlos Nelson; DAVID, Maria Beatriz de Albuquerque (org.). Agricultura, democracia e socialismo. Rio de Janeiro: Paz e Terra, 1988 (1975).

RICUPERO, Bernardo. Caio Prado Jr. como intérprete do Brasil. Revista Sinais Sociais. Rio de Janeiro, v. 7 n. 19, p. 7-42, maio-ago. 2012.

SANTOS, Marco Aurélio Martins. Eles fizeram história. In: SENRA, Nelson de Castro (coord.). O censo entra em campo: o IBGE e a história dos recenseamentos agropecuários. Rio de Janeiro: IBGE, 2014, p. 547-571.

SANTOS, Raimundo. Alberto Passos Guimarães num velho debate. Revista Estudos Sociedade e Agricultura. Rio de Janeiro, n. 2, p. 53-63, jun. 1994.

SANTOS, Raimundo. Caio Prado Júnior na cultura política brasileira. Rio de Janeiro: Mauad, 2001.

SANTOS, Raimundo. Política e agrarismo sindical no PCB. Rio de Janeiro: Fundação Astrojildo Pereira, 2002.

SANTOS, Raimundo. Alberto Passos Guimarães e a revolução agrária não camponesa. Agraristas políticos brasileiros. Brasília: Fundação Astrojildo Pereira/NEAD/MDA/ IICA, 2007a.

SANTOS, Raimundo (org.). Um clássico da Revolução Brasileira. Caio Prado Jr: dissertações sobre a Revolução Brasileira. São Paulo: Brasiliense/Fundação Astrojildo Pereira, 2007b. 
TSETUNG, Mao. Sobre a contradição. Obras escolhidas de Mao Tsetung. Tomo I. Pequim: Edições do Povo, 1975 (1937), p. 525-586. Disponível em <http://www.marxists. org/portugues/mao/1937/08/contra.htm>. Acesso em 9/11/2018.

VINHAS, Moisés. O Partidão: a luta por um partido de massas (1922-1974). São Paulo: HUCITEC, 1982. 